\title{
KMETIJE KOT ČINITELJ IN JEDRA GOSPODARSKE IN SOCIALNE PREOBRAZBE HRIBOVSKEGA SVETA
}

na primeru pore`̌ja Hudinje

\author{
Milan Natck*
}

IZVLEČEK

UDK 911.373:631.111(23)(497.12)

$\mathrm{V}$ clanku so podrobno analizirani sociockonomski dejavniki obstoja in funkcioniranja samotnih kmetij v porečju Hudinje.

ABSTRACT

UDC 911.373:631:111(23)(497.12)

FARMS AS A FACTOR OF THE ECONOMICAL AND SOCIAL TRANSFORMATIONS OF THE MOUNTAIN AREA (ON THE CASE OF THE REIVER BASIN OF HUDINJA. SE SLOVENIA)

The article presents detailed analysis of socio-economic factors of existence and function of remote farms in the river basin of Hudinja - SE Slovenia

\section{UVOD}

$\mathrm{Z}$ nastankom in razvojem industrije in drugih dejavnosti se je pricela večstranska preobrazba podcželja. Industrijska in druga nekmecka naselja so postala s svojim proizvodnim potencialon pomembna gonilna sila gospodarskih in socialnih sprememb v pokrajini. Vzroki in spodbude za preoblikovanje podeželja so prihajali iz proizvodnih usmeritev, ki so terjale med drugim večjo koncentracijo delovne sile, kot pa dotlejకe zvrsti in usmeritve kmetijstva. $Z$ industrializacijo in urbanizacijo je postalo podeželje večnamenski prostor, in sicer s svojevrstnimi funkcijami, ki so vplivale na spremembo njegove fiziognomije.

$\mathrm{V}$ primerjavi $\mathrm{z}$ dolinsko-ravninskimi predeli so imela obljudena hribovska in gorska obmoxja samosvoj razvoj. Praviloma so živela dlje casa v prometnem in gospodarskem zatišju. Neposredni vplivi vexjih neagrarnih središx so jih ponavadi obšli. Do nedavna je ostala večina hribovskih obmox̌ij odvisna od lastnega proizvodnega potenciala: polikulturnega in samooskrbnega kmetijstva, kmeckega prebivalstva in načina njegovega življenja. Kmetijstvo $\mathrm{v}$ hribovskih obmocjih ima కtevilne ovire, ki so utemeljene v naravnih sestavinah okolja (prim: Melik, 1936, 396; Gams, 1960; Žumer, 1961, 7-9; Meze, 1980, 147-148; Vrišer, 1978, 291-293).

Nekdanje hribovsko kmetijstvo je bilo uglašeno s potrebami in zahtevami gospodinjstev kakor tudi z možnostmi in danostmi geografskega okolja. Kolikor bolj se je

* Dipl.geograf, strokovni svetnik, Geografski inštitut Anton Melik ZRC SAZU, 61000 Ljubljana, Novi trg 4/II., YU 
povezovalo hribovsko kmetijstvo s svojimi neagrarnimi središci, toliko manj je bila njegova proizvodnja samooskrbna in polikulturna. $\mathrm{V}$ zadnjih treh desetlet jih so postale neagrarne zaposlitve kmeckega prebivalstva $v$ dolinskih naseljih, pa prodaja lesa in tržno usmerjena reja mesno-mlex̌ne govedi tisti čnitelj in spodbujevalec, ki korenito spreminja gospodarsko, socialno in pokrajinsko podobo hribovskega sveta. ${ }^{1}$ Vec o tem prim. Meze, 1986 in tam navedena literatura na str. 467-468.

Geografska znaxilnost hribovskega sveta je v redki in razpršeni obljudenosti, prometni zatišnosti, površinski razgibanosti in razðlenjenosti kmetijskega zemljišca, v znacilni razporeditvi kmetijskih in gozdnih površin, $v$ svojstveni podobi kmeckih domov itd. Samotne kmetije ali manjša gruðasta naselja in zaselki so prevladujoča oblika poselitve hribovskega sveta (Melik, 1933, 132-134, 137-140; 1936, 536, 539-542; Ilesix, 1950, 98 in 102). Samotna hribovska kmetija, ki ima zemljisko posest v obliki odprtega ali zaprtega celka (Melik, 1936, 445-447; Ilešx, 1950, 85-93), je najmanjša, prostorsko osamljena socialna in gospodarsko-proizvodna enota ali celica. S svojimi pokrajinskimi in prebivalstvenimi znacilnostmi ter raznovrstno proizvodno-gospodarsko usmerjenostjo pomeni enega izmed pomembnih in trajnejših vzdrževalcev in oblikovalcev kulturne pokrajine (Natek, 1989).

Hribovske samine so s svojim proizvodno-prebivalstvenim potencialom dragocen in nepogrešljiv člen v razvoju našega hribovskega sveta. V njihovem preoblikovalnem potencialu so osredotocene vse tiste pokrajinske sestavine, ki s svojimi raznovrstnimi učinki ter vzrő̌no-vzajemnimi posledicami in odnosi odlocujoče vplivajo na spremembe v pokrajini. Vecina samin predstavlja tista vitalna žarił̌a, ki usmerjajo in vzdržujejo socialni in gospodarski razvoj hribovskega sveta. Ob tem je potrcbno račnati Łe $z$ raznovrstnimi vplivi in uxinki, ki prihajajo iz vseh bližnjih neagrarnih središc. V prepletanju navedenih silnic in učinkov se nezadržno spreminjata podoba in sestava hribovske (kmetijske) pokrajine.

\section{GEOGRAFSKE ZNAČILNOSTI OBRAVNAVANEGA DELA POREČJA HUDINJE}

Hribovski del Pohudinja uvršcamo v severovzhodno slovensko predalpsko hribovje, kamor segajo že nekateri subpanonski podnebni vplivi. Na jugu so Vitanjske Karavanke (Gams, 1959, 17); geolosko sestavljene iz ozkih in podolgovatih pasov razlicno starih kamnin. Najbolj obljudena so obmoxja iz miocenskih pešenjakov in konglomeratov, medtem ko je glavnina triadnih apnencev, iz katerih so najvišji vrhovi (Špik 1108 m, Štrukljev vrh 1226 m, Basališce 1272 m, Stenica 1091 m), prekrita z mešnimi in listnatimi gozdovi. 
Povirni deli Hudinje razrezujejo južna poboxja Pohorja. Sestavljena so iz neprepustnih in silikatnih paleozojskih kamnin. S srednjevesko kolonizacijo, ki je segla do nadmorske visine (=nmv) okrog $1200 \mathrm{~m}$, so bila obljudena $\mathrm{v}$ obliki samin soncna pobocja, na katerih ljudje vztrajajo కe danes.

Med Pohorjem in Vitanjskimi Karavankami je v sklopu zgornjega Pohudinja se tretja pokrajinska enota, in sicer terciarno Vitanjsko-dolisko podolje. Po njem so bile že v preteklosti speljane prometnice, ki so povezovale alpske predele s panonskimi pokrajinami. (Podrobnosti prim.: Gams, 1959, 102; 1983, 45-46; Melik, 1957, 133; Ilešic, 1958, 109-110; Curk, 1978, 249, 250, 259 in 262).

$\mathrm{V}$ teh pokrajinskih enotah, ki s podnebnega vidika sodijo h klimatskim znacilnostim Celovške kotline in savinjskega podnebnega rajona (Gams, 1972, 6-8) in dobivajo od 1100 do $1600 \mathrm{~mm}$ padavin letno, je bilo preucenih 279 hribovskih domacij. Njihovi domovi so raztreseni od 530 do $1113 \mathrm{~m}$ in pripadajo 17 naseljem v obcinah Celje, Slovenj Gradec in Slovenske Konjice.

Vexina kmetij ima zemljißko posest v odprtih ali zaprtih celkih. Le na Paskem Kozjaku in njegovem obrobju je ncikaj zaselkov, ki imajo obdclovalno zemljo $\mathrm{v}$ obliki prvotnih grud (prim. tudi Ilešic, 1950, 23 in 24; Melik, 1936, 450).

\section{NEKATERE STABILNE GEOGRAFSKE PRVINE HRIBOVSKIH DOMAČIJ}

Stabiine oziroma počasi se spreminjajoce prvine geografskega okolja so cinitelj, ki nemalokrat odloxilno vpliva na gospodarsko usmerjenost in trdnost domacij, pa na obliko in podobo hribovskega sveta. Med stabilnejse pokrajinotvorne de javnike uvršamo povrsinske, podnebne, pedoloske, vodne in rastne razmere in znacilnosti, nadmorsko višino domov in njihovega obdelovalnega zemljiš̌a ter nagnjenost (strmino) kmetijske zemlje, ki je bila objektivna prepreka za hitrejకo uveljavitev kmetijske mehanizacije v hribovitih predelih (prim. tudi Ilesix, 1970, 10-13).

\subsection{Nadmorska vißina kmeckega doma}

Selišca preuðenih kmetij so bila v povpreeni nmv $745 \mathrm{~m}$. Domovi so segali najvisje $v$ nascljih Hudinja (v povprexju $894 \mathrm{~m}$ ), Stranice $(841 \mathrm{~m})$ in Paka (819 m), najnižje pa v krajih na južnih pobox̌jih Paškega Kozjaka (Parož $600 \mathrm{~m}$; Velika Raven $563 \mathrm{~m}$ ) in Kislice (Lipa $599 \mathrm{~m}$ ), ali na severni strani Stenice (naselje Stenica $601 \mathrm{~m}$ ). Tudi pri 
tem so opazne regionalne razlike: najvißja so bila selišca pohorskih kmetij (v povprecju $794 \mathrm{~m}$ ), za $50 \mathrm{~m}$ nižje so stali domovi karavanకkih kmetij in skoraj $90 \mathrm{~m}$ pod njimi so bile stavbe $v$ Doliškem podolju $(658 \mathrm{~m})$. Devetnajst domaxij je imelo domove $\mathrm{v} n \mathrm{~nm}$ nad $1000 \mathrm{~m}$ : te so bile $\mathrm{v}$ glavnem osredotocene $\mathrm{v}$ povirju Hudinje in na južna poboxja Paskega Kozjaka. Edinole Karl (1033 m), ki obdeluje prisojne strani Krejanovega vrha (1082 m), je na severni strani osrednjega grebena Paskega Kozjaka.

\subsection{Nadmorska viSina obdelovalnega sveta}

Spodnja meja sklenjenega obdeiovalnega sveta sega od 530 do $1040 \mathrm{~m}$. Najnižja je bila v Veliki Ravni $(480 \mathrm{~m})$, na Stenici $(546 \mathrm{~m})$ in v Parožu $(545 \mathrm{~m})$, najvišja na Hudinji (830 m), Strmcu nad Dobrno (792 m) in Stranicah (772 m). Pohorske kmetije so imele spodnji rob sklenjenega kmetijskega zemljiša v nmv $735 \mathrm{~m}$, karavanłke v $\mathrm{nmv} 681 \mathrm{~m}$, domovi v Doliskem podolju pa v nmv $598 \mathrm{~m}$.

Zgornja meja obdelovalne oziroma kmetijske zemlje je bila najvisja pri Sp. in $\mathrm{Zg}$. Arnejcu (1165 m o7. $1170 \mathrm{~m})$ na Strmcu, Ovcarju $(1160 \mathrm{~m})$ na Hudinji itd. V tem pogledu prednjačijo hudinjske $(921 \mathrm{~m})$, strmske $(920 \mathrm{~m})$, paske $(845 \mathrm{~m})$, brdske kmetije $(\$ 35 \mathrm{~m})$ itd. Pohorske kmetije so obdelovale zemljo v povpreč ju do nmv $820 \mathrm{~m}$, karavanske do $782 \mathrm{~m}$ in hribovske domaxije v Doliskem podolju do $686 \mathrm{~m}$.

ViSinska razlika med spodnjim in zgornjim robom kmetijske zemlje je pomembno krajevno dolocilo, v katerem se kaže razčlenjenost in kamninska zgradba povrß̌ja, izraba zemlje, prometni upor, proizvodni stroßki, mikroklimatske poteze in razlike itd. Skratka, v njej so zarisani కtevilni pokrajinski in gospodarski elementi, ki uxinkujejo na stopnjo gospodarnosti kmetijske proizvodnje in potrebnosti živega dela pri njenih usmeritvah, na fiziognomijo pokrajine itd.

Povprečna razlika med spodnjo in zgornjo mejo sklenjenega kmetijskega sveta je znaŠala na obravnavanem obmoxju $93 \mathrm{~m}$; najmanjకa je bila pri pohorskih $(85 \mathrm{~m})$, najve $x_{j a}$ pri karavanških domaxijah $(101 \mathrm{~m})$. Znatne so te razlike med posameznimi naselji. Najve ${ }_{j i}$ razpon med spodnjim in zgornjim robom posesti so imele kmetije na Strmcu (128 m), v Veliki Ravni $(110 \mathrm{~m})$ in Lipi (101 m), najmanjßega pa skomarske $(73 \mathrm{~m})$, zgornjeselske $(75 \mathrm{~m})$ in ljubniske domaxije $(76 \mathrm{~m})$.

Povpręna aritmetix̌na sredina kmetijske zemlje je bila v nmv $730 \mathrm{~m}$, kar je za $15 \mathrm{~m}$ pod viß̌no domov. V vseh treh delih obravnavane regije stoje domovi od 14 do $17 \mathrm{~m}$ nad povprex̌no višno njim pripadajođega zemljišca. Večina nekdanjih ornih površin je bila razmešcena v sredini posesti, medtem ko so travniki, senožeti in pašniki zavzemali obrobne in od domov oddaljene dele domaxije. 


\subsection{Strmina kmetijske zemlje}

je posebna znacilnost, ki pomeni omejitveni dejavnik in zmanjsuje gospodarnejక̌ proizvodnjo $\mathrm{v}$ hribovskih predelih. Strmina kmetijske zemlje se poveč je praviloma $z$ nadmorsko visino. Domaxije do nmv $800 \mathrm{~m}$ obdelujejo zemljo s povprečnim naklonom od $15,3^{\circ}$ do $15,5^{\circ}$, vse vißje ležeče kmetije imajo zemljo s povprečno strmino od 16,5 do $16,9^{\circ}$.

Najbolj strmo posest na obmoxju Vitanjskih Karavank imajo naselja (Stranice $20^{\circ}$, Parož $19,9^{\circ}$, Strmec $19,4^{\circ}$, Kozjak $19,2^{\circ}$ itd.) Najbolj položna je bila kmetijska zemlja na Breznu $\left(12,5^{\circ}\right)$, Stenici $\left(13,3^{\circ}\right)$, Paki $\left(14,2^{\circ}\right)$, Hudinji $\left(15^{\circ}\right)$, v Ljubnici $\left(15,5^{\circ}\right)$, Veliki Ravni $\left(15,6^{\circ}\right)$ itd. Kmetije $\mathrm{z}$ najbolj strmimi kmetijskimi povrß̌nami so na siršem obmoxju Paskega Kozjaka, in sicer v naseljih Kozjak (Gornji GolCar 28,2 ${ }^{\circ}$, Lukež

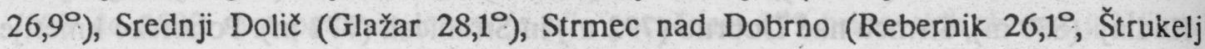
$25,7^{\circ}$, Sp. Mařic in Fridek $25^{\circ}$ ), Brdce in Parož. Edinole Konečnikova kmetija na Paki $\left(24,8^{\circ}\right)$, ki ima dom v nmv $849 \mathrm{~m}$, se more primer jati po strmini svojega sveta s karavanskimi domaxijami.

Ocitne so tudi razlike v strmini kmetijske zemlje med posameznimi predeli Pohudinja. Pohorske kmetije (v povprečju $15^{\circ}$ ) in domaxije na šršem območju Vitanjskega podolja $\left(15,5^{\circ}\right)$ so precej manj strme kot kmečka posest v predelih Vitanjskih Karavank $\left(16,3^{\circ}\right)$. Povprexna strmina kmetijske zemlje v zgornjem Pohudinju najbolj ustreza živinorejskemu tipu pašno-košnega sistema (prim. Meze, 1980, 147).

\section{NEKATERE SOCIALNO-GOSPODARSKE IN PREBIVALSTVENE ZNAČILNOSTI}

Gospodarska in prebivalstvena struktura, ki sestavljata proizvodni potencial hribovskih kmetij, odloxata o njihovi proizvodni usmerjenosti in gospodarski trdnosti. Z elcktrifikacijo, omrežjem gozdnih cest, vodovodnimi napeljavami, z mehanizacijo kmetijstva kakor tudi z zaposlitvijo v neagrarnih de javnostih ter s primarno predelavo in prodajo lesa so bili ustvarjeni pogoji, ki zmanjšjejo razlike med kmetijami v Pohudinju. Podoba je, da so velikost posesti in njena zemljißka struktura ter demografska oziroma socialna sestava prebivalstva ponovno postali dejavniki, ki soodlocajo o današnji gospodarski podobi hribovskih kmetij.

\subsection{Velikost kmetij in delež gozdov}

Kmetije v Pohudinju so merile v povprex ju po 19,94 ha, od tega je odpadlo na gozd- 
ove 11,39 ha ali $57 \%$ posesti. V povprexju so bile najvexje kmetije na obmoxju Vitanjskih Karavank (21,83 ha), nekaj manjše na Pohorju (18,63 ha) ter v naseljih Doliškega podolja (17,84 ha). Po naseljih so bile najvexje domaxije v Zg. Lindeku (25,5 ha), Sr. Dolicu (25,2 ha), na Strmcu ( 24,9 ha), Kozjaku (22,9 ha), Brdcah (22,7 ha), najmanjse na Stenici (14,5 ha), Stranicah (13 ha), v Ljubnici (15,2 ha) itd. Velikost kmetij praviloma narašca $\mathrm{z}$ višanjem nmv domov: domovom do $800 \mathrm{~m}$ je pripadalo po 18,8 ha zemlje, višje ležěim pa 22,5 ha. Ugotovljena je bila funkcijska povezanost med nmv domov in velikostjo kmetij: korelacijski koeficient za Pohudinje znaša $\mathrm{r}=$ $+0,54448$.

Gozdovi zavzemajo v povprex ju okrog $57 \%$ zemljiske posesti. Sorazmerno najvex so jih imele kmetije v Zg. Selcih (73 \%), Veliki Ravni (70 \%) in Zg. Lindeku (69 \%). Najve $\chi_{j i}$ delež kmetijske in obdelovalne zemlje so imele kmetije v Sp. Dolǐu (51\%), Ljubnici (49 \%), na Stenici (47\%), Skomarju (57\%). V sklopu zemljißke posesti so zavzemali gozdovi v Vitanjskih Karavankah $59,5 \%$, na Pohorju $56 \%$ in $52,5 \%$ na obmoxju Doliskega podolja. Gozd je pomembna gospodarska postavka sleherne hribovske domacije. Brez njega so bile, ali pa so ga imele v izjemno majhnih površnah vseh 14 (ali $5 \%$ kmetij) na obmocju zgornjega Pohudinja, ki so nastale ob agrarni reformi.

\subsection{Gospodarstvo}

V zadnjih petindvajsetih letih je razpadia polikulturna in samooskrbna kmecka proizvodnja, v kateri je bilo namenjeno žitaricam najvex njiv. Preusmerjeno poljedelstvo, ki je izgubilo nekdanjo vel javo, je namenjeno prideiovanju krompirja in drugih okopavin ter krmnih rastlin. Žita, v kolikor so se ohranila, zavzemajo majhne povrsine. $V$ glavnem pridelujejo se pšnico in le redki sejejo jeðmen, rž in oves ter tu in tam \e ajdo.

S traktorizacijo kmetijstva se je spremenila sestava živine. Vole in konje kot vprežno in delovno živino je nadomestilo večje stevilo krav - molznic in pitano govedo. Na gospodarstvo je prišlo v povprexju po 9 govedi, od tega 4 krave. Največ živine so imele kmetije na obmoxju Dolisł:ega podolja (13 glav), najmanj v Karavankah $(6,5$ glav), medtem ko so redili Pohorci po 10 glav odraslega goveda. Delež krav med govejo živino se je gibal od $42 \%$ (hribovske kmetije na obrobju podolja) do $44 \%$ (Pohorje in Karavanke). Prasicereja je namenjena domacim potrebam: kmetije v Vitanjskem podolju so imele po 4 odrasle svinje, pohorske domacije po 3,8 in na 10 karavanß̌kih domov je priß̌lo po 27 prasicev.

Mleko je prodajalo preko krajevnih zbiralnic 59 kmetij, ki so ga leta 1986 in 1987 
oddale po 6.400 I na leto. Samo ena osmina karavanskih domaxij je bila usmerjena v redno prodajo mleka; letno so ga oddale po $7.200 \mathrm{l}$. V Doliskem podolju je ena petina kmetij prodajala mleko, in sicer po 5900 l; tretjina pohorskih kmetij je oddala zbiralnicam po 6.2001 mleka na leto.

Tri ectrtine obravnavanih domaxij je dobivalo dohodek od reje in prodaje govejih pitancev in telet. $\mathrm{V}$ povprec ju je $10 \mathrm{kmetij}$ prodalo po 22 govejih pitancev: najvec na Pohorju (24 glav) in v Dolißkem podolju (25 glav), najmanj v Karavankah ( 20 govedi). Celo $85 \%$ doliskih in pohorskih kmetij je redilo in prodajalo pitano govedo, med karavanškimi domačijami le $65 \%$ gospodarstev.

Les je druga postavka, na kateri slonita obstoj in razvoj vecine kmctij v Pohudinju. Kmetije z gozdovi so imele $v$ povprečju $32,2 \mathrm{~m}^{3}$ letnega etata. Največ so ga imeie domacije v Srednjem Dolicu $\left(60 \mathrm{~m}^{3}\right)$, na Kozjaku $\left(43 \mathrm{~m}^{3}\right)$ in Skomarju $\left(40 \mathrm{~m}^{3}\right)$ pa na Hudinji $\left(39 \mathrm{~m}^{3}\right)$, Paki $\left(35 \mathrm{~m}^{3}\right)$ itd. Po $100 \mathrm{~m}^{3}$ in vec letnega etata jc imelo 11 domaxij, in največ jih je bilo z območja Vitanjskih Karavank. Toda v povprečju so imcle karavanకkc domacije najmanjsi letni ctat $\left(31 \mathrm{~m}^{3}\right)$, le za spoznanje visjega so imele pohorske $\left(34 \mathrm{~m}^{3}\right)$ kakor tudi kmetije na obmoxju Doliskega podolja $\left(36 \mathrm{~m}^{3}\right)$. V zadnjih dveh letih niso sekali lesa pri $17 \mathrm{kmetijah.}$

Traktorje je imelo $77 \%$ hribovskih kmetij. Z njimi je obdeiovalo zemljo $83 \%$ pohorskih domačij, v drugih dveh območjih pa tri cetrtine gospodarstev. Prva dva traktorja so dobili leta 1965 . Do leta 1970 so imele traktorje 4 kmetije, v desetlet ju 1971-80 jib je dobilo 142 gospodarstev in v 80 . letih Se 70 domacij. Traktcrizacija kmetijstva jc bila razlǐno intenzivna $\mathrm{v}$ posameznih predelih Pehudinja. Čctrtina pohorskih in petina karavanకkih ter doliskih kmetij je dobila prve traktorje v letih 1971-75, v naslednjen petletju, ko je bilo uvajanje kmetijske mehanizacije najintenzivncjłe, je kupilo traktorje $44 \%$ pohorskih, $58 \%$ podoljskih in $38 \%$ karavanških kmečkih gospodarstev. V 80 . letih je pripeljalo traktorje na dvoriša $27 \%$ pohorskih, $22 \%$ podoljskih in $41 \%$ karavanških kmetov.

Silosi za spravilo živinske krme so nov element v okviru kmeckih domov in kažejo na tehnolosko prenovo pridobivanja in skladišcenja krme, obencm pa kažejo na začetno prcusmeritev kmetijstva. Leta 1987 je imelo silose 61, t.j. $22 \%$ kmetij, od tega jih imata ena petina pohorskih in karavanskih domacij in $31 \%$ bribovsihih domov na obrooju Doliškega podolja. Prvi silos so postavili pri Meglič na Stenici okrog leta 1960. Pelovica silosov je bila postavljena v obdobju 1981-85; v tem pogledu ni vecjih raziik med pređeli zgornjega Pohudinja. Četrtina pohorskih kmetij je dobila silese v letih 1976-80 in cetrtina po letu 1985. Slaba cetrtina domačij v podolju je postavila silose do leta 1975 aii v obdobju po 1985 . Vex kot polovica karavanskih domov ima silose iz let 1981-85, dobra tret jina pa iz druge polovice 80 . let. 
Leta 1987 je mineralna gnojila uporabljalo $70 \%$ kmetij, in sicer v povprex ju po 1.150 kg. $Z$ njim je dognojevalo posevke in travnike $82 \%$ domaxij v Doliškem podolju, 74 $\%$ pohorskih in $62 \%$ karavanških kmetij. Najve飞 gnojila so potrosile podoljske domaxije (1384 kg), v drugih dveh obmoxjih pa petino manj $(1080 \mathrm{~kg})$. Na 1 ha kmetijske zemlje je prislo v Pohudinju $95 \mathrm{~kg}$ umetnih gnojil, od tega $134 \mathrm{~kg} / \mathrm{ha}$ na obmo¿ju Doliškega podolja, $97 \mathrm{~kg} / \mathrm{ha}$ na Pohor ju in $77 \mathrm{~kg} / \mathrm{ha}$ v Karavankah.

\subsection{Prebivalstvo}

Leta 1987 je živelo na 279 pohudinjskih kmetijah in na domovih v porečju levih pritokov Pake 1.354 prebivalcev, od tega 50,2\% moških. Najvec ljudi so imele domaðije na Skomarju (po 6 oseb), v Ljubnici $(5,5)$, Parožu $(5,4)$, Veliki Ravni $(5,2), Z_{g}$. Lindeku in na Paki (po 5 oseb). Najmanj obljudene so bile kmetije v Zg. Selcih (4 osebe), na Stenici in Stranicah $(4,3)$, Kozjaku $(4,5)$, Hudinji $(4,6)$ itd. Najvec ljudi je živelo na pohorskih kmetijah (v povpre夭ju po 5 oseb), le nekaj manj na karavanکkih $(4,8)$ in $v$ podoljskih domovih (po 4,65 ljudi).

Med prebivalstvom na kmetijah je bilo $61 \%$ aktivnega, od tega polovica moških. V tem pogledu ni veðjih razlik med posameznimi predeli zgornjega Pohudinja. Skoraj ena tretjina aktivnega prebivalstva je delala $\mathbf{v}$ neagrarnih dejavinostih. Najbolj deagrarizirane so bile karavanške domazije $(37,3 \%)$, mecitem ko je odhajalo s pohorskih domov na delo izven kmetij samo $26 \%$ za delo sposobnega prebivalstva. Med nckmexkimi zaposlenci so prevladovali moski, in sicer $\mathrm{z}$ dvema tretjinama.

Na pohudinjskih kmetijah sta delala $v$ povprexju po dva cloveka. Najve` kmeðkih delaveev so imele pohorske domaxije (po 2,3 osebe), vse druge znatno manj (po 1,8 ljudi). Med kmecko delovno silo so prevladovale ženske in le $\mathrm{z}$ dvema petinama so bili zastopani moski.

Čistih kmexkih domačij je bilo $42 \%$ : najveð na Pohorju (51,5\%), najmanj v naseijih Vitanjskih Karavank (35\%) in dve petini na šrక̌em obmoxju Doliškega podolja. Tri desetine kmetij smo uvrstili med polčiste in eno petino v skupino mešaniin gospoda:stev; siednjih je bilo najveð v podolju $(25 \%)$ in v Karavankah $(24 \%)$, najmanj v pohorskem Pohudinju (11 \%). Ena dvanajstina kmetij je imela dohodke iz nckmečkih pokojnin, kar kažc na sorazmerno zgodnjo deagrarizacijo obravnavanega ozemlja.

Danes so skoraj vse domacije povezane s cestami. Zato tudi ni veð tako oxitnih razlik med stevilom zaposlenih, kot so bile v preteklosti. Na nekmexko zaposiitev praviloma ne vplivata ne oddaljenost in ne veiikost kmetije, temved Stevilæna in starostna sestava prebivalcev v posamcznih družinah. Velenje, Vitanje, Zreð̌, Slovenske Konjicc, Celje in కe nekatera druga središa privabljajo 1judi iz zgornjega Pohudinja in jim odmer jajo precejšen del njihovega vsakdanjega kosa kruha. 


\section{SKLEP}

Gospodarska in socialno-prebivalstvena sestava opozarjata, da je vecina kmetij v koreniti proizvodni prenovi: stare oblike kmetovanja izginjajo, ali pa se stapljajo s tržno usmerjeno proizvodnjo. Hribovska obmoxja s stevilnimi posebnostmi terjajo specifixne posege $v$ preoblikovanje obstojece gospodarske in socialne strukture. Naravno-geografske danosti in prilike omejujejo, obenem pa opredeljujejo njihovo proizvodno usmerjenost. Ob opuscanju polikulturnega poljedelstva je nevarnost, da bodo postali hribovski predeli prevec enostransko usmerjeni, in sicer $v$ domeni ekstenzivne živinoreje. Organizirana kmetijska celiŁna proizvodnja, ki je znacilna za celke in zaselke, podpira prenekatere ukrepe in prizadevanja tudi na podroxju varstva okolja in sploh ohranjanja kulturne pokrajine. Kajti hribovska kmetija je gospodarsko-socialna enota - celica, ki je s svojo proizvodnjo, prebivaistvenim potencialom in $\mathrm{z}$ vsem drugim neposredno vkljucena $\mathrm{v}$ vsakdanji pokrajinski utrip; le ta se kaže $\mathrm{v}$ nacinu življenja in v spremembah podobe hribovskega sveta.

Vex̌ina kmetij je premajhna, da bi zmogle preživljati gospodarje in njịhove družine. Kolikor bolj se bodo uveljavile tržno usmerjene in mehanizirane kmetije, toliko moxnejša bo deagrarizacija kmexkega prebivalstva. Pričakovati je, da se bodo v obljudenih hribovskih predelih cedalje bolj prepletali vplivi in uxinki dcla in življenja kmexkih in vseh drugih zaposlencev, ki bodo vkljuxeni v cedalje mox̌nejš tokove dnevnega vozastva. $\mathrm{Na}$ hribovskih kmetijah prevladuje precejšen delcž domacega prebivalstva. Šcle s cestami so se odprle možnosti, da nastajajo ob njih novi domovi v nekmetijstvu zaposlenega prebivalstva. V tem je porok, da prihaja do razlixncga pokrajinskega izvora prebivalcev, kar vnaša $v$ pokrajino nove možnosti njencga razvoja. Ostarela kmexka gospodinjstva niso sposobna preusmeriti kmexkih gospodarstev, pax pa varujejo in negujejo podedovane oblike in načine kmetovanja (Makarovix, 1982, 321-322). Vccina novosti je priłla in se je uveljavila ria hribovskih kmetijah z mlaöimi, predvsem domaximi gospodarji.

Današnja preobrazba hribovskega sveta je odvisna od usmerjenosti in proizvodne uspešnosti kmetij ter socialne in demografske sestave prebivalstva. Podoba jc, cla silijo ccdalje bolj v ospredje gmotne razmere kmeckih gospodarstev in njihovih gospodinjstev. Te so ob ustreznem prebivalstvenem potencialu tista sila, ki nezadržno spreminja hribovski svet. V tej vsakdanji prenovi gospodarstva, prebivalstva in domov oziroma celotnih naselij postaja podeželje z vsemi svojimi pokrajinskimi sestavinami cedalje pomembnejši in večnamenski prostor. 


\section{LITERATURA}

1. Curk, J., 1978, Cestno omrežje na slovenskem Štajerskem v prvi polovici 19. stoletja. - ČZN, 49, nova vrsta 14, st. 2, str.238-268, Maribor.

2. Gams, I., 1959, Pohorsko Podravje. Razvoj kulturne pokrajine. Ljubljana.

3. Gams, I., 1960, O viSinski meji naseljenosti, ozimine, gozda in snega v slovenskih gorah. - Geografski vestnik, XXXII.- Melikov zbornik, str. 59-69, Ljubljana.

4. Gams, I., 1972, Prispevek h klimatogeografski delitvi Slovenije. - Geografski obzornik, XIX., st. 1, str. 1-9, L jubljana.

5. Gams, I., 1983, Geografske znaxilnosti Slovenije. Ljubljana.

6. Ilešic, S., 1950, Sistemi poljske razdelitve na Slovenskem. Ljubljana.

7. Ilešx, S., 1958, Problemi geografske rajonizacije ob primeru Slovenije. - Geografski vestnik, XXIX-XXX., str. 83-140, Ljubl jana.

S. Ilešix, S., 1970, Vloga koroške regije v slovenskem prostoru- Jugovzhodna Koroska, str. 9-25, Ljubljana.

9. Makarovic, M., 1982, Strojna in Strojanci. Narodopisna podoba koroske hribovske vasi. Ljubljana.

10.Melik, A., 1933, Kmetska naselja na Slovenskem. - Geografski vestnik, IX., str. 129-165, Ljubljana.

11.Melik, A., 1936, Slovenija. Geografski opis. 2. zvezek, Ljubljana.

12.Melik, A., 1957, Štajerska s Prekmurjem in Mežiško dolino. Ljubljana.

13.Meze, D., 1980, Osnovne smernice za geografsko prouxcvanje hribovskih kmetij na Slovenskem. - Geografski vestnik, LII., str. 145-154, Ljubljana.

14.Meze, D., 1986, Nekaj splošnih ugotovitev o hribovskih kmetijah na Slovenskem. Raziskovalec, 16, str. 464-468, Ljubljana.

15.Natek, M., 1989, Vioga prebivalstva pri ohranjevanju in spreminjanju geografskega okolja na območju Mežiske doline in jugovzhodnega Pohorja. - Prispevek na 13. kongresu geografov SFRJ v Pristini.

16.Vrišer, I., 1978, Regionalno planiranje. Ljubl jana.

17.Žumer, L., 1961, Gorsiki gospodarski prostor. - Ekonomska revija, XII., §t. 1, str. 6-26, L jubljana. 


\section{FARMS AS A FACTOR OF THE ECONOMICAL AND SOCIAL TRANSFORMATION OF THE MOUNTAIN AREA (ON THE CASE OF THE RIVER BASIN OF HUDINJA - SR SLOVENIA)}

The treated territory of the upper river basin of Hudinja consists of thre regions: in the north the Pohorje Mountains, as the outmost eastern part of the Central Alps in Slovenia is to be found. In the south there are the Vitanje Karavanke Mountains or the Konjice Mountains, between them in the derection east-west the Vitanje-Dolix valley with the tertiary rocks is situated. The Pohorje slopes consist of the impermcable and silicated paleozoic rocks. The eastern or the Vitanje Karavanke Mountains are composed of the triassic limestones and dolomites, as well as of tertiary sandstones and conglomerates.

In the upper part of the Pohudinje area the alpine and pre-alpine climatic influences with the sub-panonian characteristics interlace. The territory receives from 1000 to $1600 \mathrm{~mm}$ percipitation per year, the mean annual temperatures are between $8 \mathrm{deg}$. and $9,5 \mathrm{deg}$. $\mathrm{C}$.

The mountain areas of Poiudinje were settled in the Middle Ages. In the settlement there are the isolated mountain farms with the land tenure in the enclousers. On the southern slopes of the Karavanke the clustered hamlets are also to be found, which have thcir fields in the "clods" (champs en blocs). The old roads, some of them had built in the Roman period, connected teh Alpine and pre-A!pine regions with the Panonian regions. They were leading along the Hudinja and Vitanje valleys.

The large economic and administrative centres of upper river basin of Hudinja are located on its margin. Only Vitanje is to be found in the middle of the treated territory. With its central position and with the development of the iron-works, with the manufacture and sale of wood, Vitanje became the hart of the recent time due to the influences and cconomical stability of some larger places, which are located on the margin of the territory under consideration (Velenje, Cclje, Zre飞e, Slovenjske Konjice). All these caused a rapid deagrarization of the agricultural population and depopulation of the mountain area.

In the treaties 279 mountain farms were analysed. The house of the examined farms are situated at the altitude above sealevel from 530 to $1113 \mathrm{~m}$. In this altitude difference the whole gecgraphical picture of the mountain farming is delineated.

Some stable geograpiical elements of the mountain farms are characterized in detail. They have decisively influenced the orientation of the production and the economic stability of the farms. Among the regional farming factors are the relief, 
climatic, pedologic, water and the vegetation characteristics, as well as the altitude above sea level of the farm houses and of the agricultural land, and the gradient of the rural surfaces.

The lower limit of the cultivable land is at the altitude from 530 to $1040 \mathrm{~m}$; its average altitude is $683 \mathrm{~m}$. The average upper limit of the agricultural surface was $776 \mathrm{~m}$. The difference between the lower and upper limits of the cultivated land was on the average $93 \mathrm{~m}$. The whole picture and the problems of the mounatin agriculture can be seen in the dissected relief, lithological structure, way of land use, traffic and production expences, and in the microclimatic differences etc. The result of the mentioned factors is shown in the stage of the economy and the agricultura! production.

In the upper Pohudinje area the land tenure increased with the altitude above sea level. The average gradient of the cultivable land was from $15,3 \mathrm{deg}$ to $16,9 \mathrm{deg}$. The size of the farms was on the average 19,94 ha. - the forest occupied 58 per cent of the surface. Nowadays the cattle breeding and the forcstry are two main branches, which give to the farmers the material basis for their existence and further development. The cattle are being bred for milk and meat meant for market. The autarchic oriented farming, which had been polycultural, being to decay in the sixties of this century. The greater part of the fields were abondonet and changed into the medows and pastures.

After 1965 the agricultural mechanization was aiso introduced into the mountain area. The horses and oxen were replaced by tractors. In the Pohudinje area almost 75 per cent of the farms have the tractors. The building of silos, for the cattle food, started in the seventies of this century. At the present, 22 per cent of the treated farms have the silos.

In 1987 on the 279 farms lived 1.354 inhabitants - 50,2 per cent of them were men. Among the inhabitants living on the farms 61 per cent were active - one third of them worked in non-agrarian activities. Among the active agricultural populatin prevailed women $/ 60$ per cent), among those cmployed in non-agrarian activities prevailed men ( 67 per cent).

The author's opinion is that it is necessary, first of all, to know all the geographical characteristics of the treated territory, before any plan is made for its development. The farms with all the economical and population potentiais could indirectly influence further development of the mountain arcas. 